\title{
A Model of Collaborative Knowledge- Building
}

\section{ABSTRACT:}

This paper presents a model of learning as a social process incorporating multiple distinguishable phases that constitute a cycle of personal and social knowledge-building. It explicitly considers the relationship of processes associated with individual minds to those considered to be socio-cultural. This model of collaborative knowledge-building incorporates insights from various theories of understanding and learning in hopes of providing a useful conceptual framework for the design of CSCL software, specifically collaborative knowledge-building environments (KBEs). By naming a set of cognitive and social processes, it suggests areas for computer support, including a set of specific illustrative KBE components.

As we learn more and more about something what happens?

(a) the questions all get answered.

(b) the questions get easier and easier.

(c) the questions get more and more complex.

- adapted from a student survey in (Lamon et al., 1993)

\section{INTRODUCTION}

As we learn more and more about the learning sciences, the controversies intensify, the paradigms proliferate, the quandaries 
deepen and the foundations shake. This is how knowledge-building in a research community advances.

In the book that established the field of Computer-Supported Collaborative Learning (CSCL) and presented the state of the art at that time, the editor identified three distinct theories of learning implicit in the community's research (Koschmann, 1996):

- neo-Piagetian conflict theory

- cultural-historical activity theory

- $\quad$ social practice theory

- Recently, he has proposed two more:

- Deweyan trans-actional inquiry (Koschmann, in press)

- Bakhtinian dialogicality theory (Koschmann, 1999)

This paper takes yet another cut at the problem, incorporating insights from these theories and related philosophies.

The model presented here is an attempt to understand learning as a social process incorporating multiple distinguishable phases that constitute a cycle of personal and social knowledge-building. The cyclical character of this process allows increasingly complex questions to be posed on the basis of more and more sophisticated understanding.

This model of collaborative knowledge-building incorporates insights from theories of understanding and learning within a simplistic schema in hopes of providing a useful conceptual framework for the design of CSCL software, specifically collaborative knowledgebuilding environments. It is inquiry in the service of practical activities, as Dewey would say (Dewey \& Bentley, 1949/1991). In its own terms, it is a set of personal beliefs, articulated as a contribution to a social knowledge-building process that may lead through collaborative discourse toward the enriched self-understanding of a research community.

\section{A DIAGRAM OF PERSONAL AND SOCIAL KNOWLEDGE-BUILDING}

Despite frequent references to constructivism in the CSCL literature, it is not clear in that literature which cognitive processes are involved in collaborative knowledge-building. In particular, it continues to be unclear to skeptical readers of this literature what the relationship is of collaborative group processes to individual cognitive processes. This, 
despite the fact that each of the theories of learning described by Koschmann goes to great pains to conceptualize this relationship.

A set of seminal papers in CSCL has formulated a perspective on learning as a social process of collaborative knowledge-building (Brown \& Campione, 1994; Lave, 1991; Pea, 1993; Scardamalia \& Bereiter, 1996). However, these papers do not make the set of cognitive processes that underlie such a view explicit in the manner attempted here.

This paper presents a diagram (Figure 1) that represents a number of important phases in collaborative knowledge-building. The convention in the diagram is that arrows represent transformative processes and that rectangles represent the products of these processes: forms of knowledge. To take this limited representation too seriously would be to reify a complex and fluid development - to put it into boxes and to assume that it always follows the same path. In particular, the diagram gives the impression of a sequential process whereas the relations among the elements can take infinitely varied and complex forms. Indeed the identification of the particular set of elements is arbitrary and incomplete. Perhaps despite such limitations and potential distortions the diagram can provide a starting point for discussing a cognitive theory of computer support for knowledge-building. It remains to be seen if such a phase model provides the most useful representation.

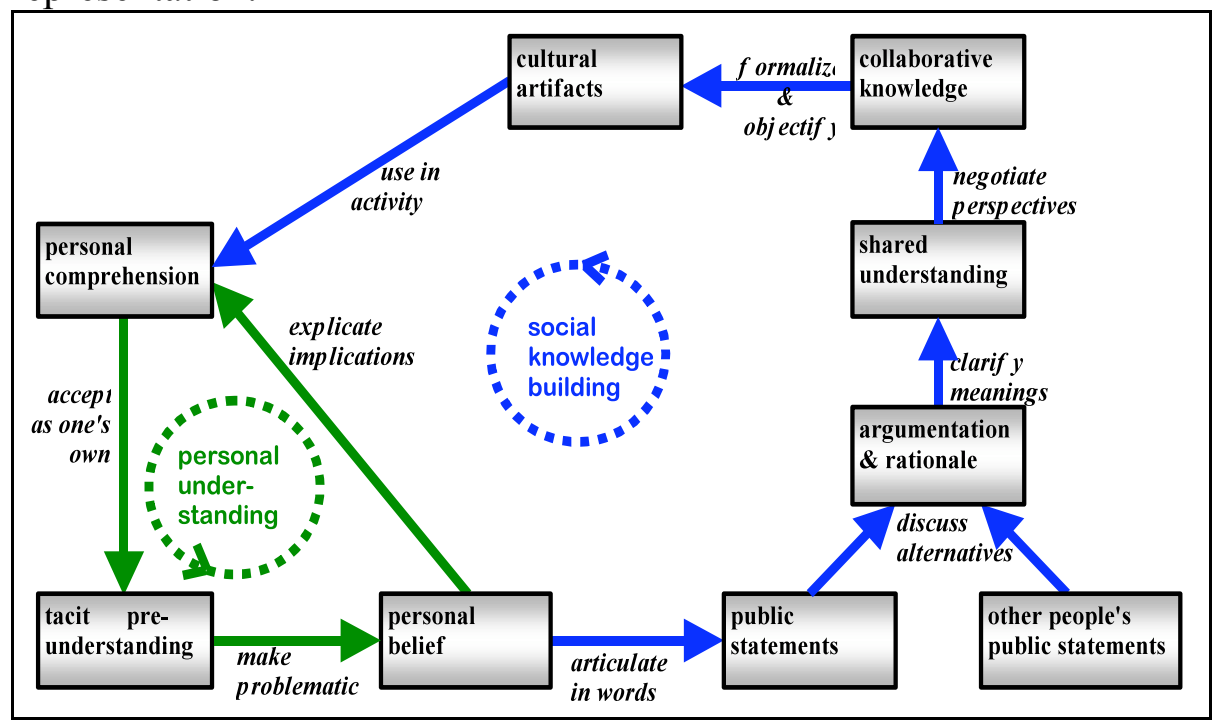


Figure 1. A diagram of knowledge-building processes.

The diagram attempts to model the mutual (i.e., dialectical) constitution of the individual and the social as a learning process (Brown \& Duguid, 1991; Lave \& Wenger, 1991). Starting in the lower left corner, it shows the cycle of personal understanding. The rest of the diagram depicts how personal beliefs that we become aware of in our activity in the world can be articulated in language and enter into a mysterious social process of interaction with other people and with our shared culture. This culture, in turn, enters into our personal understanding, shaping it with ways of thinking, motivational concerns and diverse influences. Personal cognition and social activity can only be separated artificially, as in a model like this designed for analysis. That is the nature of a relationship of mutually constituting subjects: neither can exist without the other, but it is useful to distinguish them at certain points in their analysis (Hegel, 1807/1967).

\section{THE CYCLE OF PERSONAL UNDERSTANDING}

Martin Heidegger (Heidegger, 1927/1996) (an important recent German philosopher) and Donald Schön (1983) (an influential American theoretician of design) argue that learning starts on the basis of tacit pre-understanding (Polanyi, 1962; Stahl, 1993a; Winograd \& Flores, 1986). Some form of breakdown in planning or in our worldly activity renders elements of this tacit understanding problematic on occasion (Dewey \& Bentley, 1949/1991). The network of meanings by which we make sense of our world is torn asunder and must be mended. The resolution of the problem proceeds through a gnawing awareness of the problematic nature of some piece of our understanding. We may be able to repair our understanding by explicating the implications of that understanding and resolving conflicts or filling in gaps - by reinterpreting our meaning structures to arrive at a new comprehension. This typically involves some feedback from the world: from our experience with artifacts such as our tools and symbolic representations. If we are successful and the problem disappears, this new comprehension gradually settles in to become our new tacit understanding and to provide the starting point for future understanding and further learning. 
The process of interpretation that seems to be carried out at the level of the individual mind is already an essentially social process. The network of "personal" meanings ultimately has its origin in interpersonal language and culture. Interpretation takes place within language (Wittgenstein, 1953), history (Gadamer, 1960/1988), culture (Bourdieu, 1972/1995; Bruner, 1990; Cole, 1996), social structures (Giddens, 1984) and politics (Habermas, 1981/1984). Our "internal" thought process capabilities and structures themselves have origins in our previous social interactions (Mead, 1934/1962; Vygotsky, 1930/1978). Our personal interpretive perspective or voice is a consolidation of many perspectives and voices or genres of others we have known (Bakhtin, 1986; Boland \& Tenkasi, 1995). However, this social context and origin is hidden because it has been incorporated into the tacit pre-understandings of the individual and can only be made visible by means of the methodological alienation of scientific approaches (Heidegger, 1927/1996; Husserl, 1954).

It is not always possible to resolve the problematic character of our personal understanding internally, particularly when it is provoked by other people. Then we may need to enter into an explicitly social process and create new meanings collaboratively. To do this, we typically articulate our initial belief in words and express ourselves in public statements.

\section{THE CYCLE OF SOCIAL KNOWLEDGE-BUILDING}

We then enter the larger sequence of processes represented in the diagram. Here we can build upon and supplement the cycles of individual learning of several individuals. This happens when someone's personal belief is articulated in words and this public statement is taken up in a social setting and discussed from the multiple perspectives of several participants. The original statements are thereby articulated into a more refined and extensive discussion of the topic, subject to conflicting interpretations. The discussion consists of arguments providing rationale for different points of view. The interchange may gradually converge on a shared understanding resulting from a clarification of differences in interpretation and terminology. 
If the communication is relatively free of hidden agendas, power struggles and un-discussed prejudices, then arguments and clarifications can lead to agreement or at least mutual understanding. If the negotiation of the different perspectives does result in acceptance of a common result, then such a result is accepted as knowledge. In this way, collaboration and undistorted communication mediate between personal belief and accepted knowledge.

Underlying the theory of learning defined by this diagram is a social epistemology. Individuals generate personal beliefs from their own perspectives, but they do so on the basis of socio-cultural knowledge, shared language and external representations. Further, these beliefs become knowledge through social interaction, communication, discussion, clarification and negotiation. Knowledge is a socially mediated product.

The fact that knowledge is a product of social communication does not mean that it is ungrounded or arbitrary. The medium of knowledge - language - is grounded in the life experiences of individuals, in our physical embodiment, in our sense of rationality, in the interaction patterns of communicating communities, in cultural traditions and in the vast background knowledge that is implicitly accepted in every act of understanding or agreement. Furthermore, the communication process that results in knowledge incorporates argumentation that can introduce empirical evidence and logical deduction from other established knowledge. Scientific methodologies have their legitimate and legitimating roles within the communication process of their respective communities. But it is always the case that negotiated agreement on the issues and methodologies as well as on the conclusions is required in order to promote claims to the status of knowledge. And such knowledge is never absolute - although its character is to be taken as final truth - but always subject to the possibility of future questioning, reinterpretation and renegotiation.

The public statements that result from the discussion, argumentation and clarification form a shared language, created through the communication process. The communication process takes place on several levels: propositional content, perspective-taking, social interaction, repair of misunderstandings, latent connotations, etc. This language and analysis is negotiated by the public group and becomes their shared collaborative knowledge. The resultant understanding exists only in the public communication that took place, although it can 
subsequently be incorporated into each participant's individual learning process.

Note that the individual mind (left side of the diagram in Figure 1) is indispensable to the larger cycle, providing both the starting and the ending point - as well as being involved at each social phase in ways not adequately represented in the diagram. Conversely, the individual mind is intimately intertwined with the intersubjective (right side of diagram), solving its problems through the use of public language and constantly internalizing cultural meanings.

From a cognitive viewpoint, there are of course many skills and subprocesses at work that are not represented in the diagram. These include activities considered personal skills, like summarization, text understanding, critical thinking, logical structuring of arguments. They also include social interaction skills such as turn-taking, repair of misunderstandings, rhetorical persuasion, interactive arguing. For simplicity sake, the diagram ignores these detailed phases and various other, similar options. It also ignores the unlimited paths that can be followed by the over-all process and the manifold interactions of the individual and social levels. A diagram like this is highly selective, illustrating a few prominent processes and ignoring many alternatives and details. The nomenclature for the stages of the processes is particularly inadequate to express what is pictured, for we have only very impoverished ways of talking about these processes and their interactions. Nevertheless, such a diagram can provide a helpful external memory (Donald, 1991), cognitive artifact (Norman, 1993) or "object to think with" (Papert, 1980) in developing a theoretical understanding.

Collaborative understandings are sometimes objectified in external persistent symbolic objects - cultural artifacts - that preserve this understanding as their meaning. The meaning encapsulated in the artifact comes to life when the artifact is used. This coming to life in use by an individual is an interpretive process of the individual's activity in the world. It may take place either consciously or tacitly, and may subsequently be integrated into the individual's implicit personal understanding. In this way, among others, social meanings become internalized in personal minds. Another way this may happen is through formalization of the shared understanding in representational schemas that express the shared knowledge. These representations are also cultural symbolic objects that help to transmit and encapsulate 
collaborative knowledge. Formal representations like mathematical symbol systems or our process diagram provide cognitive supports and help to preserve and communicate meanings, much like physical cultural artifacts such as sculptures do in their own way (Stahl, 1999b).

\section{OPPORTUNITIES FOR COMPUTER SUPPORT}

By defining a sequence of typical phases of social knowledgebuilding, the diagram suggests a set of focal points where computer support may be desirable. It thereby provides a conceptual framework for the design, use and assessment of collaborative KnowledgeBuilding Environments (KBEs). Table 1 proposes a form of computer support corresponding to each phase in the diagram's social knowledge-building cycle. Of course, one cannot provide computer support for individual cognition per se; personal beliefs must be articulated as public statements before they can interact within computer media. In fact, thoughts must be even more formalized for computer support than for interpersonal interaction (Stahl, 1993b).

Table 1. Forms of computer support for phases of knowledge building.

\begin{tabular}{|l|l|l|}
\hline & Phase of knowledge building & Form of computer support \\
\hline a & articulate in words & articulation editor \\
\hline b & public statements & personal perspective \\
\hline c & other people's public statements & comparison perspective \\
\hline $\mathbf{d}$ & discuss alternatives & discussion forum \\
\hline e & argumentation \& rationale & argumentation graph \\
\hline $\mathbf{f}$ & clarify meanings & glossary discussion \\
\hline $\mathbf{g}$ & shared understanding & glossary \\
\hline $\mathbf{h}$ & negotiate perspectives & negotiation support \\
\hline $\mathbf{i}$ & collaborative knowledge & group perspective \\
\hline $\mathbf{j}$ & formalize and objectify & bibliography discussion \\
\hline $\mathbf{k}$ & $\begin{array}{l}\text { cultural artifacts } \\
\text { and representations }\end{array}$ & $\begin{array}{l}\text { bibliography } \\
\text { or other community repository }\end{array}$ \\
\hline
\end{tabular}

a) Computer support for learning should facilitate the process of articulating ideas and preserving them in convenient forms. A text editor or simple word processor is a minimal 
instance of this. Some KBEs have tried to introduce procedural facilitation, scaffolding or prompting to encourage someone to articulate an appropriate expression (Slotta \& Linn, in press). For instance, in order to start someone articulating their initial belief, an editor might open with the words, "I believe that ... because ...." already entered. Other approaches would be to provide an outline editor or a brainstorming area.

b) Public statements by one person confront those of other people. Computer support can represent the different perspectives from which these statements emerge. Perspectives are more general than representations of individuals themselves, because one person can offer statements from multiple perspectives and several people can agree on a common perspective. Perspectives can be related to one another, for instance deriving from a common perspective that they share. Computational representations of perspectives should make explicit the important relationships among personal and group perspectives, as well as providing means for individuals and collaborative teams to articulate their own perspectives in a KBE (Stahl, 2000).

c) A KBE with support for perspectives should provide comparison perspectives, in which one can view and contrast alternative perspectives and adopt or adapt ideas from other people's perspectives. The idea of a comparison perspective is that it aggregates ideas from various individual and/or group perspectives and allows for easy comparison of them. This is an important source of bringing ideas together to foster convergence of thinking and sharing of insights or interpretations (Stahl, 1999b).

d) The most common element in current KBEs is the discussion forum. This is an asynchronous, interactive communication system that allows people to respond to notes posted by one another. Typically, there is a thread of responses to entered notes, with a tree of divergent opinions. A KBE should go beyond superficial undirected discussion to converge on shared understandings and acknowledged ideas (Hewitt, 1997). 
e) Although every note in a discussion forum is a response to another note, the discussion may have a more complex implicit structure. One note might argue for or against another or provide evidence to back up the claim of another note, for instance. Such an argumentation structure can be made explicit and formalized in a representation of the argumentation graph. A component that supported this could contribute to participants' meta-level comprehension of their knowledge-building process, pointing out where additional evidence is needed or where alternatives have not been explored (Donath, Karahalios, \& Viegas, 1999).

f) An important requirement for constructing group knowledge is the establishment of shared understanding. This can be fostered by clarifying the meaning of important terms used in various competing claims. A glossary discussion can make explicit how different participants understand the terms they use. The discussion can go on to converge on common understandings by sharing perspectives or negotiating conventions.

g) The glossary discussion should result in a group glossary of the agreed upon definitions of important terms. Such a glossary already represents a form of group knowledge. The glossary is, of course, subject to future debate and emendation; it may make sense to define the glossary as a particular display of information from the glossary discussion (Stahl \& Herrmann, 1999).

h) Perhaps the most delicate phase of knowledge-building is negotiation. Power differentials of all kinds generally enter at this point. The power of established authority resists the negotiation of change. Computer support of negotiation tends by nature to make explicit the factors entering into the negotiation process. This can be extremely harmful to the subtle processes of persuasion if not done sensitively. On the other hand, negotiation is critical to helping multiple perspectives to converge on shared knowledge. Computer support can provide a useful tool - as long as it is carefully integrated with other social processes that allow for implicit, culturally established interpersonal interactions (Stahl, 1999a). 
i) The accumulation of negotiated shared knowledge results in the establishment of a group perspective. Like the alternative individual and team perspectives, the group perspective may be represented in a KBE. The content of the group perspective should be inherited into the individual and team perspectives, because it is now accepted by them. Individuals can then build on this shared knowledge within their own perspective and even begin to critique it and start the whole cycle over.

j) Shared knowledge is not the final phase in the cycle of social knowledge-building. The knowledge can be further formalized. While it must have already been expressed explicitly at least in written language within the KBE, it can now be represented in another symbolic system or combined into a more comprehensive system of knowledge. For instance, in academic research knowledge is incorporated in new classroom lectures, conference presentations, journal articles and books. These venues bring the ideas into broader communities of discussion - widening the social circle that may accept or revise the new knowledge. The discussion of knowledge that has been compiled into publications can be carried out in a bibliography discussion component of a $\mathrm{KBE}$ (Stahl, 1993b).

k) Finally, representations of the new shared knowledge in publications and other cultural artifacts are themselves accepted as part of the established paradigm. Although still subject to occasional criticism, ideas in this form more generally provide part of the accepted base for building future knowledge. In academic circles, an annotated bibliography of such sources might provide a useful $\mathrm{KBE}$ component to support this phase of knowledge building.

Of course, the preceding suggestions of possible KBE components are simply illustrative of the kinds of supports that might be designed for KBEs based on the analysis of the knowledge-building process outlined above. They are meant to evoke a particular approach to software design. 


\section{THE IDEA OF A COMPUTER SYSTEM TO SUPPORT THE KNOWLEDGE-BUILDING PROCESS}

A KBE should go beyond a single-purpose system - like a simple discussion forum - and support more than one phase of the social knowledge-building process. It should retain a record of the knowledge that was built up - unlike common chat, newsgroup and listserv systems that erase contributions after a short period of time. It should therefore probably be built on asynchronous, persistent collaborative technologies and be deployed on the Internet as a Web-based environment.

A KBE should support at least several of the lifecycle phases of knowledge-building. It should help people to express their beliefs, to discuss them with others, to differentiate their own perspectives and adopt those of other people, clarify disagreements or misunderstandings, critique and explicate claims, negotiate shared understandings or agreements, and formulate knowledge in a lasting representation.

Because KBEs are computational, they should provide facilities like searching, browsing, filtering, tailoring and linking. Beyond that they could incorporate heuristics that automatically suggest relevant connections, critique problems in the knowledge base and deliver information automatically when it might be useful. They can also compile and format sets of notes in convenient displays. KBEs can interface with other software and systems, sending for instance emails to notify collaborators when important events have taken place.

Although there are significant difficulties in implementing and successfully deploying such complex systems, their potential advantages seem extraordinary: they can provide a range of supports for what is generally a difficult, painful and obscure process of knowledge-building. They introduce explicit structures for an otherwise haphazard sequence of uncoordinated events. Not only are the knowledge products made persistent in the computer memory, but much of the process is retrievable later. Historical analyses can be carried out and decision points revisited. The asynchronous nature of the communication allows participants to be more reflective and significantly reduces scheduling problems and time limitations. The computer basis permits computational mechanisms like searching, reorganizing, browsing, filtering, indexing and matching. An essential 
requirement of collaboration is making things public; a KBE renders many aspects of the knowledge-building process public that otherwise remain hidden from the participants. The social nature of the process and its products is rendered visible - and therefore the fact that the group has the power to evolve the knowledge further is also made evident.

\section{CONCLUSION}

A $\mathrm{KBE}$ is a software environment intended to support collaborative learning. The process model of knowledge-building presented in this paper provides a conceptual framework for the design, use and assessment of such systems by indicating important phases that could be supported.

In broad terms, computer support should provide a workspace in which ideas can be articulated, can come into interaction with other ideas from multiple viewpoints, can be further developed and can approach consensus. It should afford, facilitate or even encourage this multi-phased community process. It should provide a convenient medium to formulate, represent and communicate ideas at the various phases. And it should preserve the ideas and their various formulations in its computer-based medium to allow for review, reflection and continuation at any time or from any place.

As the model suggests, collaborative learning is a complex process. Given the constraints on community members who lead busy, geographically distributed lives, KBEs have the potential to provide computationally-supported communication media to facilitate this process that forms a centerpiece of the learning sciences.

\section{ACKNOWLEDGMENTS}

This paper was motivated by modeling sessions with Thomas Herrmann and Kai-Uwe Loser during a visit to the University of Dortmund in June 1999 and recent exchanges with Tim Koschmann. It has benefited from comments by collaborators in the author's Fall '99 seminar on KBEs, participants in the CSCL ' 99 workshop on KBEs and the ICLS reviewers. 


\section{REFERENCES}

Bakhtin, M. M. (1986). The problem of speech genres (V. McGee, Trans.). In C. Emerson \& M. Holquist (Eds.), Speech genres and other late essays (pp. 60-102). Austin, TX: University of Texas Press.

Boland, R. J., \& Tenkasi, R. V. (1995). Perspective making and perspective taking in communities of knowing. Organization Science, 6(4), 350-372.

Bourdieu, P. (1972/1995). Outline of a theory of practice (R. Nice, Trans.). Cambridge, UK: Cambridge University Press.

Brown, A., \& Campione, J. (1994). Guided discovery in a community of learners. In K. McGilly (Ed.), Classroom lessons: Integrating cognitive theory and classroom practice (pp. 229-270). Cambridge, MA: MIT Press.

Brown, J. S., \& Duguid, P. (1991). Organizational learning and communities-of-practice: Toward a unified view of working, learning, and innovation. Organization Science, 2(1), 40-57.

Bruner, J. (1990). Acts of meaning. Cambridge, MA: Harvard University Press.

Cole, M. (1996). Cultural psychology. Cambridge, MA: Harvard University Press.

Dewey, J., \& Bentley, A. (1949/1991). Knowing and the known. In J. A. Boydston (Ed.), John Dewey: The later works, 1925-1953 (Vol. 16). Carbondale, IL: SIU Press.

Donald, M. (1991). Origins of the modern mind: Three stages in the evolution of culture and cognition. Cambridge, MA: Harvard University Press.

Donath, J., Karahalios, K., \& Viegas, F. (1999). Visualizing conversation. Journal of Computer Mediated Communication, 4(4). Retrieved from http://www.ascusc.org/jcmc/vol4/issue4/donath.html.

Gadamer, H.-G. (1960/1988). Truth and method. New York, NY: Crossroads.

Giddens, A. (1984). The constitution of society. Berkeley, CA: U of California Press. 
Habermas, J. (1981/1984). Reason and the rationalization of society (T. McCarthy, Trans. Vol. One). Boston, MA: Beacon Press.

Hegel, G. W. F. (1807/1967). Phenomenology of spirit (J. B. Baillie, Trans.). New York, NY: Harper \& Row.

Heidegger, M. (1927/1996). Being and time: A translation of Sein und Zeit (J. Stambaugh, Trans.). Albany, NY: SUNY Press.

Hewitt, J. (1997). Beyond threaded discourse. Paper presented at the WebNet '97.

Koschmann, T. (1996). Paradigm shifts and instructional technology. In T. Koschmann (Ed.), CSCL: Theory and practice of an emerging paradigm (pp. 1-23). Mahwah, NJ: Lawrence Erlbaum.

Koschmann, T. (1999). Toward a dialogic theory of learning: Bakhtin's contribution to learning in settings of collaboration. Paper presented at the Computer Supported Collaborative Learning (CSCL '99), Palo Alto, CA. Retrieved from http://kn.cilt.org/csc199/A38/A38.HTM.

Koschmann, T. (in press). A third metaphor for learning: Toward a form of trans-actional inquiry into inquiry. In D. Klahr \& S. Carver (Eds.), Cognition and instruction: 25 years of progress. Mahwah, NJ: Lawrence Erlbaum.

Lamon, M., Chan, C., Scardamalia, M., Burtis, P. J., \& Brett, C. (1993). Beliefs about learning and constructive processes in reading: Effects of a computer supported intentional learning environment (csile). Paper presented at the Annual Conference of the American Educational Research Association (AERA '93), Atlanta, GA.

Lave, J. (1991). Situating learning in communities of practice. In L. Resnick, J. Levine \& S. Teasley (Eds.), Perspectives on socially shared cognition (pp. 63-83). Washington, DC: APA.

Lave, J., \& Wenger, E. (1991). Situated learning: Legitimate peripheral participation. Cambridge, UK: Cambridge University Press.

Mead, G. H. (1934/1962). Mind, self and society. Chicago, IL: University of Chicago Press.

Norman, D. A. (1993). Things that make us smart. Reading, MA: Addison-Wesley Publishing Company. 
Papert, S. (1980). Mindstorms: Children, computers and powerful ideas. New York, NY: Basic Books.

Pea, R. (1993). The collaborative visualization project. Communications of the ACM, 36(5), 60-63.

Polanyi, M. (1962). Personal knowledge. London, UK: Routledge \& Kegan Paul.

Scardamalia, M., \& Bereiter, C. (1996). Computer support for knowledge-building communities. In T. Koschmann (Ed.), CSCL: Theory and practice of an emerging paradigm (pp. 249-268). Hillsdale, NJ: Lawrence Erlbaum Associates.

Stahl, G. (1993a). Supporting situated interpretation. Paper presented at the Annual Meeting of the Cognitive Science Society (CogSci '93), Boulder, CO. Retrieved from http://www.cis.drexel.edu/faculty/gerry/publications/conferences/19901997/cogsci93/CogSci.html.

Stahl, G. (1993b). Interpretation in design: The problem of tacit and explicit understanding in computer support of cooperative design. Unpublished Ph.D. Dissertation, University of Colorado, Boulder, CO. Retrieved

from http://www.cis.drexel.edu/faculty/gerry/publications/dissertations/comp uter.

Stahl, G. (1999a). Reflections on WebGuide: Seven issues for the next generation of collaborative knowledge-building environments. Paper presented at the Computer Supported Collaborative Learning (CSCL '99), Palo Alto, CA. Retrieved from http://www.cis.drexel.edu/faculty/gerry/publications/conferences/1999/ $\underline{\csc 199 / .}$.

Stahl, G. (1999b). WebGuide: Guiding collaborative learning on the web with perspectives. Paper presented at the Annual Conference of the American Educational Research Association (AERA '99), Montreal, Canada. Retrieved from http://www.cis.drexel.edu/faculty/gerry/publications/conferences/1999/ aera99/.

Stahl, G., \& Herrmann, T. (1999). Intertwining perspectives and negotiation. Paper presented at the International Conference on Supporting Group Work (Group '99), Phoenix, AZ. Retrieved from 
http://www.cis.drexel.edu/faculty/gerry/publications/conferences/1999/ group99/group99.pdf.

Stahl, G. (2000). Collaborative information environments to support knowledge construction by communities. AI \& Society, 14, 1-27. Retrieved from http://www.cis.drexel.edu/faculty/gerry/publications/journals/ai\&societ $\mathrm{y} /$.

Vygotsky, L. (1930/1978). Mind in society. Cambridge, MA: Harvard University Press.

Winograd, T., \& Flores, F. (1986). Understanding computers and cognition: A new foundation of design. Reading, MA: Addison-Wesley.

Wittgenstein, L. (1953). Philosophical investigations. New York, NY: Macmillan. 